\title{
Role of Pleural Biopsy in the Etiological Diagnosis of Exudative Pleural Effusion
}

\author{
Jamal Uddin Ahmed ${ }^{1 *}$, Mohammad Delwar Hossain²*, Farhana Afroz ${ }^{3}$, Muhammad Abdur Rahim4, AKM \\ Musa $^{5}$
}

\begin{abstract}
Purpose: Exudative pleural effusion usually indicates an underlying pulmonary pathology. Sometimes etiological diagnosis of exudative pleural effusion is difficult despite cytological, biochemical and microbiological tests. Aim of present study was to make an etiological diagnosis of exudative pleural effusion by pleural biopsy.

Methods: This cross-sectional observational study was performed from January 2012 to December 2014 in the Department of Internal Medicine \& Pulmonology of BIRDEM General Hospital, Dhaka, Bangladesh. A total of 51 patients with exudative pleural effusion in whom the diagnosis was uncertain after routine biochemical, cytological and microbiological evaluation of pleural fluid were included in the study. These patients underwent pleural biopsy by Abram's needle and histopathology was done to determine the etiology of pleural effusion.

Results: Majority (74.5\%) of the patients were male. Mean age of the patients was $52.7 \pm 16.0$ years. Most (52.9\%) patients had right sided pleural effusion. Histopathology report of the pleural biopsy showed granulomatous inflammation compatible with tuberculosis (TB) in 15 (29.4\%), metastatic malignancy in 10 (19.6\%) and chronic inflammation in 9 (17.6\%) cases. In 17 (33.3\%) cases the histopathology did not reveal any abnormality. Among 10 cases of metastatic malignancy, most (7, 70\%) were adenocarcinoma. Compared to malignancy cases, TB cases were younger in age (Mean age: TB - $45.0 \pm 17.9$ vs malignancy - $61.8 \pm 13.0$ years). Pleural fluid was straw color in all (100\%) cases of TB and hemorrhagic in almost all (90\%) cases of metastatic malignancy (p 0.000). Mean value of pleural fluid protein (59.1 $44.8 \mathrm{vs} 47.3 \pm 4.2 \mathrm{gm} / \mathrm{L} ; \mathrm{p}$ 0.003), lactate dehydrogenase (LDH) $(917.3 \pm 219.3 \mathrm{vs} 464.3 \pm 112.3$ $U / L ; p$ 0.101), adenosine deaminase (ADA) (39.0 $3.7 \mathrm{vs} 15.615 .6 \pm 2.3 \mathrm{U} / \mathrm{L} ; \mathrm{p}$ 0.016), total leukocyte count (1039.3 \pm 776.8 vs $439.2 \pm 138.2 \mathrm{cells} / \mathrm{cmm} ; p$ 0.328) and lymphocyte percentage $(94.4 \pm 4.3 \mathrm{vs} 68.3 \pm 9.3 ; p 0.003)$ were all raised in TB compared to metastatic malignancy.
\end{abstract}

Conclusions: Pleural biopsy was definitive diagnostic in almost half the patients with exudative pleural effusion. Tuberculosis was more common than malignancy particularly in young persons. Pleural fluid protein, LDH and ADA are significantly raised in TB compared to malignancy.

Keywords: Exudative pleural effusion, pleural biopsy, tuberculosis.

\section{Introduction:}

Accumulation of serious fluid in the pleural space is known as pleural effusion. There are over 50 causes of pleural effusions, even though a small number of diagnoses are responsible for the vast majority of effusions. ${ }^{1}$ Pleural effusion can be transudative or exudative type. ${ }^{2}$ Transudative pleural effusion is low in protein content and is usually due to some systemic diseases like cardiac, renal or hepatic disorders. But exudative pleural effusion which is high in protein content, is mostly due to underlying pleural pathology like tuberculosis (TB) or other infection and malignancy. ${ }^{3}$ So, etiological diagnosis of exudative pleural effusion is essential.

As many as $15 \%$ to $20 \%$ of all pleural effusions remain undiagnosed despite intensive efforts. ${ }^{4}$ The most common causes of undiagnosed exudative pleural effusion are tuberculosis and malignancy. ${ }^{5}$ In majority of patients, the diagnosis is apparent by history, physical examination and investigations of pleural fluid. In those, where reaching the diagnosis fails, the help of invasive diagnostic modalities is required. One of these modalities is percutaneous needle biopsy of parietal pleura. By closed pleural biopsy, around $50 \%$ of undiagnosed exudative pleural effusions could be diagnosed. ${ }^{6}$ Closed pleural biopsy is highly diagnostic for two most important causes of exudative pleural effusion - pleural tuberculosis and malignancy. ${ }^{7}$

Although the first closed biopsy of pleura was done in 1955 using Vim Silverman needle ${ }^{8}$; biopsy has traditionally been performed blindly using an Abram's pleural biopsy needle since 1958 as the technique is easy to perform, safe and inexpensive. ${ }^{9}$ Subsequently Cope and Radja introduced different types of needle and occasionally Tru-cut biopsy needle is used. ${ }^{10-12}$

The objective of the present study was to make an etiological diagnosis of exudative pleural effusion where cytological, biochemical and microbiological examinations of pleural fluid failed to confirm the etiological diagnosis. The role of percutaneous needle biopsy from parietal pleural using Abram's needle in cases of undiagnosed exudative pleural effusion was evaluated.

\section{Materials and Methods:}

This cross-sectional observational study was performed from January 2012 to December 2014 in the Department of Internal Medicine \& Pulmonology of BIRDEM General Hospital, Dhaka, Bangladesh, a tertiary care hospital for diabetic as well as non-diabetic patients. Seventy two consecutive cases 
of pleural effusion were evaluated clinically, radiologically and by thoracocentesis. Subsequently biochemical (protein, LDH, ADA), cytological (cell type, cell count and malignant cells) and microbiological (Gram and Ziehl-Nielsen stain, culture) tests of pleural fluid were done to determine the etiology of effusion. Apart from the routine investigations, other specific investigations were done according to the clinical setting. If the etiological diagnosis was confirmed by these investigations, then that patient was excluded from the study. When these investigations of pleural fluid were not able to make an etiological diagnosis, it was labeled as undiagnosed exudative pleural effusion and was subjected to pleural biopsy after obtaining proper informed consent. The patients with bleeding diatheses or taking anticoagulants, hemodynamic instability, respiratory failure, empyema, local skin infection and non-cooperation were excluded from the study. Fifty one patients were eligible for the study.

The procedure of pleural biopsy was done in sitting posture of patients. The affected side of chest was determined and the site for biopsy was selected. This area was cleaned thoroughly with antiseptics and then infiltrated with local anesthetic $(1 \%$ lignocaine). Aspiration of pleural fluid in the same syringe confirmed the presence of free fluid. For the free access, small incision of $0.5 \mathrm{~cm}$ size was made just above the upper border of the rib of selected site. The Abram's needle was introduced through it. Multiple biopsies were taken with the needle by multiple passes. After biopsy, skin incision was sutured with a single stitch. Post-biopsy chest X-ray was taken to rule out the iatrogenic pneumothorax. Pleural tissue obtained was placed in formalin containing vials for histopathological examination. All the patients were closely followed up after pleural biopsy to observe for any complications and were managed accordingly.

1. Dr. Jamal Uddin Ahmed, FCPS (Medicine). Assistant Professor, Internal Medicine \& Pulmonology, BIRDEM General Hospital and Ibrahim Medical College, Shahbag, Dhaka 1000.

2. Dr. Mohammad Delwar Hossain, MD (Chest). Associate Professor, Internal Medicine \& Pulmonology, BIRDEM General Hospital and Ibrahim Medical College, Shahbag, Dhaka 1000.

3. Dr. Farhana Afroz, FCPS (Medicine). Registrar, Internal Medicine \& Pulmonology, BIRDEM General Hospital and Ibrahim Medical College, Shahbag, Dhaka 1000.

4. Dr. Muhammad Abdur Rahim, FCPS (Medicine). Assistant Professor, Nephrology, BIRDEM General Hospital and Ibrahim Medical College, Shahbag, Dhaka 1000.

5. Prof. AKM Musa, FCPS (Medicine), MCPS, DTCD. Professor and Head of the Department of Medicine, BIRDEM General Hospital and Ibrahim Medical College, Shahbag, Dhaka 1000.

* Since both the first two authors have equal contribution to the article, they both will be considered as first or dual author of the article.

\section{Corresponding Author:}

Dr. Jamal Uddin Ahmed

FCPS (Medicine). Assistant Professor

Internal Medicine \& Pulmonology

BIRDEM General Hospital and Ibrahim Medical College

Shahbag, Dhaka 1000

e-mail: jmldollar@gmail.com

\section{Results:}

Out of 51 patients, $38(74.5 \%)$ were male, $13(25.5 \%)$ were female. Most of the patients $(42,82.4 \%)$ were diabetic. Mean age of the patients was $52.7 \pm 16.0$ years (Range: $20-93$ ). The side of pleural effusion was right sided in $27(52.9 \%)$, left sided in $22(43.1 \%)$ and bilateral in $2(3.9 \%)$ cases. Pleural fluid was straw color in $38(74.5 \%)$ and hemorrhagic in 13 $(25.5 \%)$ cases.

Histopathology report of the pleural biopsy showed granulomatous inflammation compatible with $\mathrm{TB}$ in 15 (29.4\%), metastatic malignancy in $10(19.6 \%)$ and chronic inflammation in $9(17.6 \%)$ cases. In $17(33.3 \%)$ cases the histopathology did not reveal any abnormality. Among 10 cases of metastatic malignancy, most (7, 70\%) were adenocarcinoma. (Table-I) Pleural biopsy was definitive diagnostic in almost half $(25,49.0 \%)$ the cases.

Mean age of the TB cases was lower than malignancy cases [45.0 \pm 17.9 vs $61.8 \pm 13.0$ years]. Regarding gross appearance of pleural fluid, it was straw color in $38(74.5 \%)$ cases $(100 \%$ cases of TB) and hemorrhagic in $13(25.5 \%)$ cases $(90 \%$ cases of metastatic malignancy) (p 0.000). (Table -II)

When the pleural biopsy histopathology findings were examined against pleural fluid analysis report, it was found that the mean value of pleural fluid protein $(59.1 \pm 4.8 \mathrm{vs}$ $47.3 \pm 4.2 \mathrm{gm} / \mathrm{L} ; \mathrm{p} 0.003), \mathrm{LDH}(917.3 \pm 219.3 \mathrm{vs} 464.3 \pm 112.3$ $\mathrm{U} / \mathrm{L} ; \mathrm{p}$ 0.101), ADA (39.0 \pm 3.7 vs $15.615 .6 \pm 2.3 \mathrm{U} / \mathrm{L} ; \mathrm{p} 0.016)$, total leukocyte count $(1039.3 \pm 776.8$ vs $439.2 \pm 138.2$ cells/cmm; p 0.328) and lymphocyte percentage ( $94.4 \pm 4.3$ vs $68.3 \pm 9.3 ; \mathrm{p}$ 0.003) were all raised in TB compared to metastatic malignancy. (Table-III)

In 5 patients with chronic inflammation and 4 patients with inconclusive pleural biopsy findings, anti-tubercular therapy was given considering clinico-radiological features and all improved. In 2 cases of normal biopsy findings subsequent diagnosis of bronchial carcinoma was made by fiber-optic bronchoscopy and computed tomography (CT) guided fine needle aspiration cytology (FNAC).

Table I: Pleural Biopsy Findings $(\mathrm{n}=51)$

\begin{tabular}{lcc}
\hline Pleural biopsy findings & Frequency & Percentage \\
\hline Granulomatous Inflammation & 15 & 29.4 \\
compatible with (TB) & & \\
Metastatic adenocarcinoma & 7 & 13.7 \\
Metastatic squamous cell carcinoma & 2 & 3.9 \\
Metastatic small cell carcinoma & 1 & 2.0 \\
Chronic inflammation & 9 & 17.6 \\
Inconclusive & 17 & 33.3 \\
\hline
\end{tabular}


Table 2: Evaluation of pleural biopsy histopathology findings against pleural fluid color

\begin{tabular}{lcc}
\hline Pleural Biopsy Finding & Pleural fluid color & P value \\
\hline & $\begin{array}{c}\text { Straw color } \\
\text { Number (\%) }\end{array}$ & $\begin{array}{c}\text { Hemorrhagic } \\
\text { Number (\%) }\end{array}$ \\
Granulomatous compatible with (TB) & $15(100 \%)$ & 0 \\
Inflammation ( $\mathrm{n}=15)$ & $1(10 \%)$ & $9(90 \%)$ \\
Metastatic Malignancy $(\mathrm{n}=10)$ & 8 & 1 \\
Chronic Inflammation $(\mathrm{n}=9)$ & 14 & 3 \\
Inconclusive $(\mathrm{n}=17)$ & & 0.000 \\
\hline
\end{tabular}

Table 3: Evaluation of pleural biopsy histopathology findings against pleural fluid findings

\begin{tabular}{lccccc}
\hline Pleural fluid parameter (Mean) & \multicolumn{2}{c}{ Pleural Biopsy Finding } & \multicolumn{2}{c}{ P value } \\
\hline & $\begin{array}{c}\text { Granulomatous } \\
\text { Inflammation (TB) }\end{array}$ & $\begin{array}{c}\text { Metastatic } \\
\text { Malignancy }\end{array}$ & $\begin{array}{c}\text { Chronic } \\
\text { Inflammation }\end{array}$ & Inconclusive \\
Protein (gm/L) & $59.1 \pm 4.8$ & $47.3 \pm 4.2$ & $47.7 \pm 8.2$ & $47.0 \pm 9.7$ & 0.003 \\
LDH (U/L) & $917.3 \pm 219.3$ & $464.3 \pm 112.3$ & $551.3 \pm 137.2$ & $573.1 \pm 113.9$ & 0.101 \\
ADA (U/L) & $39.0 \pm 3.7$ & $15.6 \pm 2.3$ & $29.6 \pm 5.9$ & $25.2 \pm 9.1$ & 0.016 \\
Total leukocyte count /cmm & $1039.3 \pm 776.8$ & $439.2 \pm 138.2$ & $571.1 \pm 465.9$ & $1142.3 \pm 986.4$ & 0.328 \\
Lymphocyte \% & $94.4 \pm 4.3$ & $68.3 \pm 9.3$ & $85.1 \pm 25.1$ & $91.4 \pm 9.9$ & 0.003 \\
\hline
\end{tabular}

\section{Discussion:}

Most of the patient were male in this study. The probable reasons are in our society male more commonly come for medical help and smoking related lung malignancy are more in male. Mean age of the patients was more in malignancy cases than TB cases. This is similar to the findings in other study. ${ }^{13}$ This is because malignancy develops in old age but TB can affect any age.

The pleural fluid was straw color in most $(74.5 \%)$ of the cases. In all the cases of tubercular effusion the color of pleural fluid was straw and in $90 \%$ cases of metastatic malignancy, pleural fluid was hemorrhagic in color. This is similar to one study where most of the malignant effusion was hemorrhagic. ${ }^{14}$

Pleural biopsy showed that almost $30 \%$ patient had granulomatous inflammation, $20 \%$ had metastatic malignancy. Non-specific inflammation was seen in almost $20 \%$ patients. This is similar to other studies. ${ }^{6,15,16}$ Among the pleural malignancy, metastatic adenocarcinoma was the most frequent type (70\%) of malignancy found. This is similar to some other study. ${ }^{13}$ Our diagnostic yield of $20 \%$ for malignancy is comparatively low as compared to some other study, where the diagnostic yield was ranging from $30 \%$ to $70 \%{ }^{17}$ This may be due to high prevalence of $\mathrm{TB}$ in our country, making frequency of malignancy relatively low.

In this study pleural biopsy was definitive diagnostic in almost half the cases. Our finding is exactly similar to the findings in a Saudi Arabian study ${ }^{6}$ and almost similar to other studies worldwide. ${ }^{7,16,18}$ Baum GL et al described 51\% diagnostic yield of pleural biopsy in a meta-analysis of 14 studies comprising of 2839 patients. ${ }^{19}$

Pleural fluid protein, ADA. LDH were all comparatively elevated in patients with TB than malignancy. This finding is similar to other study. ${ }^{15}$ So in a undiagnosed case of exudative pleural effusion where pleural biopsy is not possible, highly elevated pleural fluid ADA and LDH may point to a diagnosis of pleural TB.

Common complications of pleural biopsy include vasovagal reaction, pain at biopsy site, seepage of pleural fluid, site hematoma, pneumothorax and pulmonary edema. Most common complication that we encountered was mild pain at biopsy site which resolved with non-steroidal anti-inflammatory drugs (NSAIDs). We did not come across any major complications in this study, illustrating the safety of this procedure.

This study was a single center study with limited number of cases. Future multi-center study with large number of cases can yield more valuable inferences.

\section{Conclusion:}

This study suggests that TB and metastatic malignancy are the two most common causes of undetermined exudative pleural effusion. Moreover, pleural fluid gross appearance as well as biochemistry and cytology can hint to the underlying diagnosis. The role of closed pleural biopsy in cases of exudative pleural effusion is still pivotal as it yields a specific diagnosis in a significant number of cases. This is of 
particular importance in our set up where tuberculosis is very common and the facilities of thoracoscopy and imaging guided cutting needle biopsies are not easily available. In view of low cost, safety and easy availability, blind pleural biopsy could be considered supplementary in the diagnostic workup of exudative pleural effusion in developing countries with limited medical resources.

\section{References:}

01. Hooper C, Lee YC, Maskell N. Investigation of a unilateral pleural effusion in adults: British Thoracic Society Pleural Disease Guideline 2010. Thorax 2010; 65 Suppl 2:ii4-17.

02. Light RW. Diagnostic principles in pleural disease. Eur Respir J 1997; 10: 476-81.

03. Saguil A, Wyrick K, Hallgren J. Diagnostic Approach to Pleural Effusion. Am Fam Physician 2014; 90 (2): 99-104.

04. Hirsh A, Ruffie P, Nebut M, Bignon J, Chretien J. Pleural effusion: Laboratory tests in 300 cases. Thorax 1979; 34:106-12.

05. Solooki M, Miri M. Approach to undiagnosed exudative pleural effusion: the diagnostic yield of blind pleural biopsy. Caspian J Intern Med 2013; 4(2): 642-47.

06. Al-Shimemeri AA, Al-Ghadeer HM, Giridhar HR. Diagnostic yield of closed pleural biopsy in exudative pleural effusion. Saudi Med J 2003; $24: 282-86$

07. James P, Gupta R, Christopher DJ, Balamugesh T. Evaluation of the diagnostic yield and safety of closed pleural biopsy in the diagnosis of pleural effusion. Indian J Tuberc 2010; 57:19-24.

08. DeFrancis N, Kloske E, Albano E. Needle biopsy of the parietal pleura-preliminary report. N Eng J Med 1955; 252: 948-99.
09. Abram's LD. A pleural biopsy punch. Lancet 1958; 1: 30-31.

10. Cope C. New pleural biopsy needle. JAMA 1958; 167: 1107-8.

11. Ogirala RG, Agarwal V, Aldrich TK. Radja pleural biopsy needle. A comparison with the Abrams needle in experimental pleural effusion. Am Rev Respir Dis 1989; 139: 984-87.

12. McLeod DT, Ternouth I, Nkanza N. Comparison of the Tru-cut biopsy needle with the Abram's punch for pleural biopsy. Thorax 1989; 44: 794-96.

13. Bhattacharya S, Bairagya TD, Das A, Mandal A and Das SK. Closed Pleural Biopsy is Still Useful in the Evaluation of Malignant Pleural Effusion. J Lab Physicians 2012; 4(1): 35-38.

14. Villena V, López-Encuentra A, García-Luján R, Echave-Sustaeta J, Martínez CJ. Clinical implications of appearance of pleural fluid at thoracentesis. Chest 2004; 125 (1):156-59.

15. Pandit S, Chaudhuri AD, Datta SBS, Dey A and Bhanja P. Role of pleural biopsy in etiological diagnosis of pleural effusion. Lung India 2010; 27(4): 202-4.

16. Biswas A, Bhatracharya S. Diagnostic role of closed pleural biopsy in the investigation of exudative pleural effusions. J Indian Med Assoc 2008; 106 (8): 525-26.

17. Menzies R, Charbonneau M. Thoracoscopy for the diagnosis of pleural diseases. Ann Intern Med 1991; 114:271-76.

18. Devkota KC, Chokhani R, Gautam S. Diagnostic yield of pleural biopsy in exudative pleural effusion. Nepal Med Coll J 2014; 16(1):13-6.

19. Baum GL, Crapo JD, Celli BR, Karlinsky JB, eds. Pleural anatomy, physiology, and diagnostic procedures. Textbook of pulmonary diseases. 6th ed. New York. Lippincot - Raven 1997: 255-65. 